\title{
QVA149 demonstrates superior bronchodilation compared with indacaterol or placebo in patients with chronic obstructive pulmonary disease
}

\author{
Jan A van Noord, ${ }^{1}$ Roland Buhl, ${ }^{2}$ Craig LaForce, ${ }^{3}$ Carmen Martin, ${ }^{4}$ Francis Jones, ${ }^{4}$ \\ Michael Dolker, ${ }^{5}$ Tim Overend ${ }^{4}$
}

'Department of Respiratory Diseases, Atrium Medisch Centrum, Heerlen, The Netherlands

${ }^{2}$ Pulmonary Department, Mainz University, Mainz, Germany

${ }^{3}$ North Carolina Clinical Research, Raleigh, North Carolina, USA

${ }^{4}$ Novartis Horsham Research Centre, West Sussex, UK ${ }^{5}$ Novartis Pharmaceuticals Corporation, East Hanover, New Jersey, USA

\section{Correspondence to} Dr Jan A van Noord, Department of Respiratory Diseases, Atrium Medisch Centrum, Heerlen, The Netherlands; j.a.vannoord@atriummc.n

Received 30 March 2010 Accepted 2 September 2010 Published Online First 26 October 2010
ABSTRAC

Background This randomised, double-blind, placebo controlled, four-period crossover study assessed the efficacy and safety of once-daily OVA149, a dual bronchodilator consisting of the long-acting $\beta_{2}$-agonist indacaterol and the long-acting muscarinic antagonist glycopyrronium (NVA237), in patients with moderate to severe chronic obstructive pulmonary disease (COPD).

Methods Patients $(N=154)$ were randomly assigned to receive OVA149 (indacaterol/NVA237) 300/50 $\mu \mathrm{g}$, indacaterol $300 \mu \mathrm{g}$, indacaterol $600 \mu \mathrm{g}$, or placebo, once daily for 7 days with a 7-day washout period between each treatment. The primary endpoint was trough forced expiratory volume in $1 \mathrm{~s}\left(\mathrm{FEV}_{1}\right)$ (mean of $23 \mathrm{~h} 15 \mathrm{~min}$ and $23 \mathrm{~h} 45$ min post-dose values) on day 7. Other endpoints included trough $\mathrm{FEV}_{1}$ on day 1 , individual time point $\mathrm{FEV}_{1}$ and monitoring and recording of all adverse events.

Results A total of 135 (87.7\%) patients completed the study (all randomly assigned patients: mean age 61.7 years, $61.4 \%$ male, post-bronchodilator $\mathrm{FEV}_{1} 52.2 \%$ predicted, $\mathrm{FEV}_{1} /$ forced vital capacity $\left.47.6 \%\right)$. The estimated treatment difference $(95 \% \mathrm{CI})$ for trough $\mathrm{FEV}_{1}$ on day 7 between OVA149 and placebo was $226 \mathrm{ml}$ (192 to 260; $p<0.001$ ). The estimated treatment difference between OVA149 and indacaterol 300 and $600 \mu \mathrm{g}$ was $123 \mathrm{ml}$ (89 to 157; $\mathrm{p}<0.001$ ) and $117 \mathrm{ml}$ (83 to 150; $p<0.001$ ), respectively. The improvements in mean trough $\mathrm{FEV}_{1}$ exceeded the predefined minimal clinically important differences of 100-140 ml for OVA149 versus placebo and indacaterol. Similar results were observed on day 1. All treatments were well tolerated.

Conclusions OVA149 demonstrated rapid and sustained bronchodilation with significant improvements compared with indacaterol monotherapy and placebo in patients with COPD.

Clinical trial registration NCT00570778.

Bronchodilators are the mainstay for the treatment of chronic obstructive pulmonary disease (COPD). ${ }^{1}$ The long-acting $\beta_{2}$-agonists (LABA), formoterol and salmeterol, and the long-acting muscarinic antagonist (LAMA) tiotropium are widely used as maintenance treatment for COPD. When symptoms are not adequately controlled by monotherapy, combining bronchodilators of different classes, in particular an inhaled muscarinic antagonist with a $\beta_{2}$-agonist, is associated with better outcomes. ${ }^{1}$

Combining LABA with anticholinergic agents has been shown to be pharmacologically useful because $\beta_{2}$-agonists decrease the release of acetylcholine, leading to consequent amplification of the bronchial smooth muscle relaxation induced by the anticholinergic agent. ${ }^{2}$ The addition of an anticholinergic agent can also reduce peripheral bronchoconstrictor effects of acetylcholine, consequently causing amplification of bronchodilation elicited by the $\beta_{2}$-agonist through direct stimulation of smooth muscle $\beta_{2}$-adrenoceptors. ${ }^{2}$ The superior bronchodilation obtained by combining bronchodilators with different mechanisms of action may be attributed to complementary pharmacodynamic profiles whereby the anticholinergic causes prolonged bronchodilation and the LABA contributes to bronchodilation and a rapid onset with greater peak effect. ${ }^{3-5}$ A number of studies have shown LABA/LAMA combinations to improve bronchodilation significantly compared with either agent used alone. ${ }^{6-10}$

Most studies published to date have reported on the combination of a twice-daily LABA with tiotropium ${ }^{3}{ }^{6-14}$ or twice-daily LABA with short-acting muscarinic antagonists. ${ }^{15} 16$ Although formoterol is not approved for once-daily administration, a combination of tiotropium and formoterol given once daily provided additional benefit over either formoterol twice daily and tiotropium once daily. ${ }^{6}$ In addition, the most favourable bronchodilation was achieved with this combination and significantly higher peak and average forced expiratory volume in $1 \mathrm{~s}\left(\mathrm{FEV}_{1}\right)$ and forced vital capacity (FVC) responses were observed compared with either component. Therefore, a combination of a once-daily LABA and a once-daily LAMA should provide further benefits over $24 \mathrm{~h}$ and may have the potential to improve patient convenience and compliance and therefore improve outcomes.

QVA149, an inhaled combination of two 24-h bronchodilators, the LABA indacaterol and the LAMA NVA237, is in development for COPD. The efficacy of both component monotherapies as oncedaily therapies has been demonstrated, and both have been shown to be safe and well tolerated. ${ }^{17-23}$ The aim of the current study was to examine the bronchodilatory effect and safety of QVA149 in patients with moderate to severe stable COPD.

\section{METHODS \\ Subjects}

Male or female patients ( $\geq 40$ years) with moderate to severe $\mathrm{COPD}^{1}$ and smoking history of 10 packyears or greater were enrolled. Patients with a postbronchodilator $\mathrm{FEV}_{1}$ of $30 \%$ or greater and less than $80 \%$ of predicted normal and post-bronchodilator 
$\mathrm{FEV}_{1} / \mathrm{FVC}$ less than 0.70 (both measurements taken 30 min following inhalation of $4 \times 100 \mu \mathrm{g}$ puffs of salbutamol) were included. Exclusion criteria were the following: requiring daily oxygen therapy, hospitalisation for an exacerbation of airway disease in 6 weeks before study start, respiratory tract infection, any history of asthma (including childhood asthma), prolonged QTc interval, or any other clinically relevant medical conditions. Pregnant or nursing (lactating) women, and women of childbearing potential, unless using acceptable methods of contraception, were excluded. Patients with a history of untoward reactions to any of the study drugs or unable to use a single-dose dry powder inhaler device or a pressurised metered dose inhaler (rescue medication) or perform spirometry measurements were excluded.

Treatment with any bronchodilators other than those prescribed in the study and inhaled corticosteroids (ICS) were not permitted during the study. During screening, LABA were changed to regular short-acting $\beta_{2}$-agonists. Salbutamol was permitted only as rescue medication during the treatment period. The steroid component of any fixed-dose combination therapy was to be replaced with an equivalent dose of ICS administered as a single agent. Patients previously treated with an ICS as a single agent (ie, not in a fixed-dose combination) were to continue on their pre-study inhaled steroid regime.

\section{Study design}

This was a randomised, double-blind, placebo controlled, fourperiod crossover, multicentre study. Following screening, eligible patients were randomly assigned to a sequence of treatments with the following once-daily regimens: QVA149 (indacaterol/ NVA237) (300/50 $\mu$ g); indacaterol $300 \mu \mathrm{g}$; indacaterol $600 \mu \mathrm{g}$ or placebo, all administered by means of a single-dose dry powder inhaler $\left(\right.$ Breezhaler $\left.^{\circledR *}\right)$. The study had four 7-day treatment periods with a 7-day washout period between each treatment. The study protocol was reviewed and approved by the independent ethics committee or institutional review board of each participating centre. The study was conducted according to the Declaration of Helsinki. Written informed consent was obtained from each subject before enrolment.

\section{Assessments}

The primary endpoint was trough $\mathrm{FEV}_{1}$ on day 7 , defined as the mean of the $23 \mathrm{~h} 15 \mathrm{~min}$ and $23 \mathrm{~h} 45 \mathrm{~min}$ post-dose $\mathrm{FEV}_{1}$ values. Other variables included trough $\mathrm{FEV}_{1}$ on day 1 , trough $\mathrm{FVC}$ at days 1 and 7, individual time point $\mathrm{FEV}_{1}$ and FVC on days 1 and 7. Pre-dose spirometry measurements on the various study days were taken in the morning between 08:00 and 10:00 hours, and all subsequent assessments were scheduled for the same clock time. Spirometry measurements were taken in a central laboratory using a Vitalograph 6800 machine provided by Biomedical Systems, Brussels, Belgium. Up to five efforts per time point were measured and experiments were to be repeatable at least three times per the American Thoracic Society/European Respiratory Society guidelines. In addition, changes in trough and individual time point inspiratory capacity (IC) were measured. FEV 1 and FVC were measured at 45 and 15 min before the first dose of study treatment (baseline), and at 5, 15 and $30 \mathrm{~min}, 1,2,3,4 \mathrm{~h}, 23 \mathrm{~h}$ $15 \mathrm{~min}$ and $23 \mathrm{~h} 45 \mathrm{~min}$ post-dose on day 1 . On day $7, \mathrm{FEV}_{1}$ and FVC were performed at 45 and $15 \mathrm{~min}$ pre-dose and 5, 15, $30 \mathrm{~min}$, $1,2,3,4,5,6,8,10,12,23 \mathrm{~h} 15 \mathrm{~min}$ and $23 \mathrm{~h} 45 \mathrm{~min}$ post-dose. Standardised $\mathrm{FEV}_{1}$ area under the curve (AUC) between $5 \mathrm{~min}$ and $4 \mathrm{~h}$ post-dose $\left(\mathrm{AUC}_{5 \min -4 \mathrm{~h}}\right.$ ), and $5 \mathrm{~min}$ and $23 \mathrm{~h} 45 \mathrm{~min}$ post-dose (AUC ${ }_{5 \mathrm{~min}-23 \mathrm{~h} 45 \mathrm{~min}}$ ) on day 1 and between $5 \mathrm{~min}$ and $4 \mathrm{~h}$ post-dose

* Breezhaler is a registered trademark of Novartis Pharma AG, Basel, Switzerland.
$\left(\mathrm{AUC}_{5 \mathrm{~min}-4 \mathrm{~h}}\right), 5 \mathrm{~min}$ and $12 \mathrm{~h}$ post-dose $\left(\mathrm{AUC}_{5 \mathrm{~min}-12 \mathrm{~h}}\right)$ and $5 \mathrm{~min}$ and $23 \mathrm{~h} 45 \mathrm{~min}$ post-dose $\left(\mathrm{AUC}_{5 \mathrm{~min}-23 \mathrm{~h} 45 \mathrm{~min}}\right.$ ) on day 7 were also determined. Peak FEV 1 (defined as the maximum $\mathrm{FEV}_{1}$ value from $5 \mathrm{~min}$ to $4 \mathrm{~h}$ post-dose) was measured on days 1 and 7 of each treatment period. IC measurements were taken for the scheduled post-dose time points: $30 \mathrm{~min}, 1,2$ and 4 h on day 1 and day 7, at 8 and $12 \mathrm{~h}$ on day 7 of each treatment period. Safety assessments consisted of recording all adverse events $(\mathrm{AE})$ and serious $\mathrm{AE}$, with their severity, duration and relationship to the study drug. In addition, regular monitoring of haematology, blood chemistry and urine, vital signs (pulse rate, blood pressure), physical condition and body weight were assessed. ECG measurements were also made before and after taking the study drug.

\section{Statistical analysis}

Patients were randomly assigned to one of the treatment sequences using an automated system. Blinding was to be maintained from randomisation until database lock unless any patient emergencies arose. The efficacy analysis population used a treatment-as-received convention, whereas the safety population used a treatment-as-assigned convention. The modified intent-to-treat (mITT) population included all randomly assigned patients who received at least one dose of the study drug. The mITT and safety populations were the same except that the safety population allowed the inclusion of non-randomly assigned patients who received the study drug by error. The primary analysis population for efficacy was the mITT population.

The primary variable, trough $\mathrm{FEV}_{1}$ on day 7 , was analysed using an analysis of covariance with the following model.

Trough $\mathrm{FEV}_{1}$ at day 7 =sequence effect + patient (sequence) + period effect+treatment effect + (period) baseline $\mathrm{FEV}_{1}+$ error A similar model was used for other efficacy variables.

A difference of $120 \mathrm{ml}$ in trough $\mathrm{FEV}_{1}$ between QVA149 300/ $50 \mu \mathrm{g}$ and placebo was considered a clinically important difference for COPD patients. ${ }^{24}$ A sample size of 36 evaluable patients was required to detect this difference between OVA149 300/50 $\mu \mathrm{g}$ and placebo as statistically significant at the $5 \%$ significance level (two-sided) with $90 \%$ power. A difference of $60 \mathrm{ml}$ in trough $\mathrm{FEV}_{1}$ between QVA149 300/50 $\mathrm{g}$ and indacaterol $300 \mu \mathrm{g}$ was considered a clinically important difference for COPD patients.

A sample size of 112 evaluable patients was required to detect this difference between OVA149 300/50 $\mu \mathrm{g}$ and indacaterol $300 \mu \mathrm{g}$ as statistically significant at the $5 \%$ significance level (two-sided) with $85 \%$ power. Assuming a drop-out rate of $20 \%$, a sample size of 140 patients was chosen to provide greater than 99\% power for the primary endpoint (trough $\mathrm{FEV}_{1}$, OVA149 300/ $50 \mu \mathrm{g}$ vs placebo) and $85 \%$ power for the key secondary endpoint (trough $\mathrm{FEV}_{1}$, QVA149 300/50 $\mu \mathrm{g}$ vs indacaterol $300 \mu \mathrm{g}$ ). Least squares mean, standard errors and associated 95\% CI for QVA149 $300 / 50 \mu \mathrm{g}$ and placebo are presented. The estimated treatment differences for QVA149 versus placebo were presented along with the associated $95 \% \mathrm{CI}$ and $\mathrm{p}$ value (two-sided). Adjustment for multiplicity was made through a hierarchial test approach for the analyses of primary and key secondary variables. First, the superiority of QVA149 over placebo was evaluated using trough $\mathrm{FEV}_{1}$ on day 7. If QVA149 was found to be superior over placebo, the superiority of QVA149 over indacaterol was evaluated in a similar manner. Assessments of vital signs and QTc (Fridericia's) were analysed using analysis of covariance.

\section{RESULTS}

\section{Patient disposition}

A total of 154 patients was randomly assigned and 135 (87.7\%) completed the study (figure 1). A total of 19 patients 
Figure 1 Patient disposition.

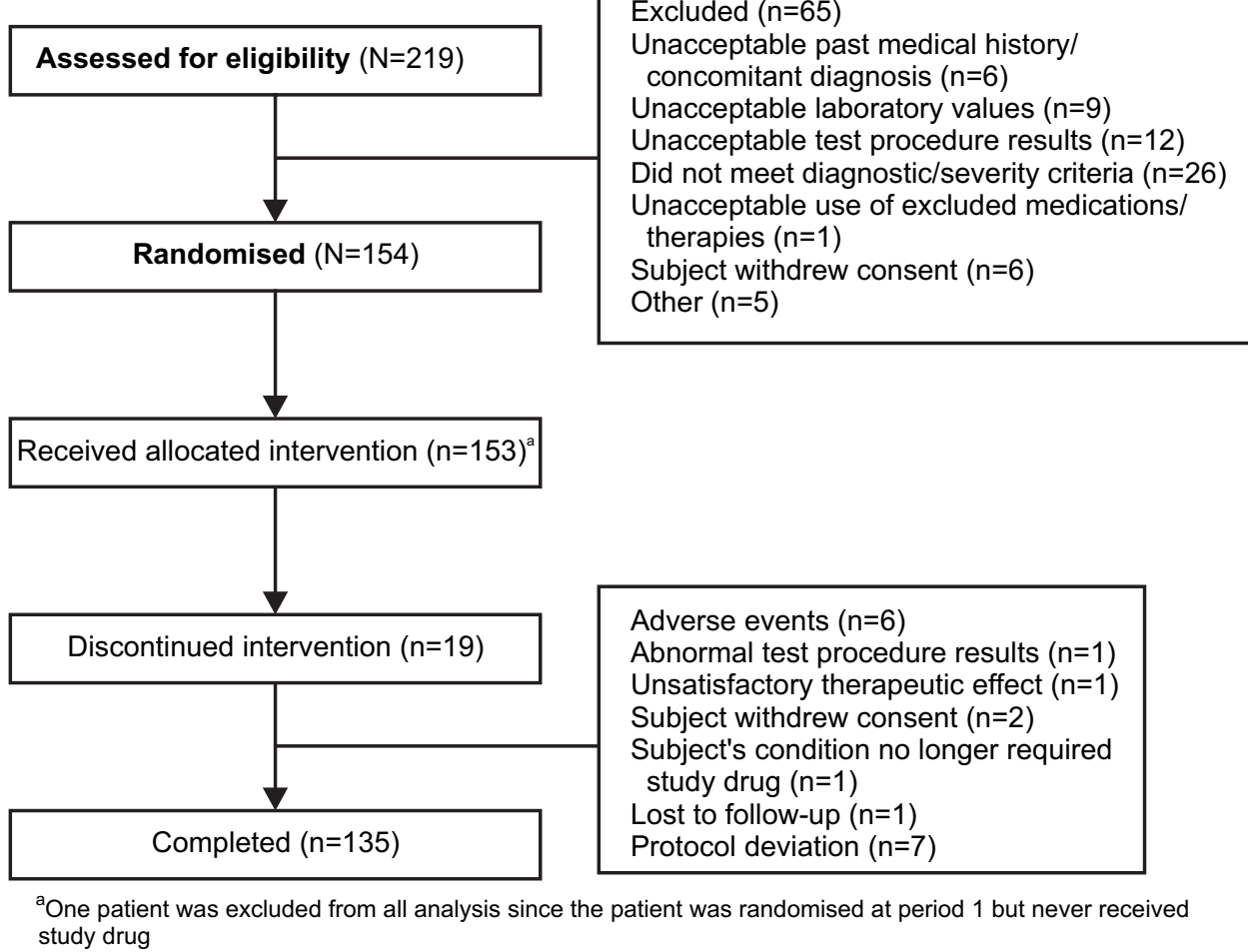

discontinued the study, with the majority $(n=10)$ of the discontinuations occurring during the first treatment period. The main reasons for premature withdrawal were protocol deviations, AEs, and either received study drug and not randomised or randomised but did not receive study drug.

\section{Patient demographics and baseline clinical characteristics}

Patient demographics and baseline characteristics are summarised in table 1 . The mean age of all patients was 61.7 years; the majority of patients were male (61.4\%) and Caucasian (98.7\%). The duration of COPD was on average 7.9 years (table 1 ).

The average pre-bronchodilator $\mathrm{FEV}_{1}$ in the study was 1.31 $\left(\mathrm{FEV}_{1}\right.$ percentage predicted: 45.3) and the average $\mathrm{FEV}_{1}$ reversibility was $17.2 \%$. Patients showed a relatively high reversibility at baseline (17.2\%) despite any history of asthma or childhood asthma being an exclusion criterion. The post-bronchodilator $\mathrm{FEV}_{1} / \mathrm{FVC}$ ratio was $47.6 \%$ and the mean post-bronchodilator $\mathrm{FEV}_{1}$ percentage predicted was $52.2 \%$, indicating that the patient population comprised moderate to severe COPD patients with airflow limitation that was not fully reversible. Approximately half of the patients were ex-smokers with the remainder being current smokers. Baseline ECG were reported as normal or as having clinically insignificant abnormalities.

\section{Efficacy}

The least squares mean trough $\mathrm{FEV}_{1}$ on day 7 for QVA149 300/ $50 \mu \mathrm{g}$ was superior to placebo (difference $226 \mathrm{ml}$ ) and indacaterol 300 and $600 \mu \mathrm{g}$ (difference 123 and $117 \mathrm{ml}$, respectively) $(p<0.0001)$. Likewise, OVA149 was superior $(p<0.0001)$ to all other treatments on day 1 (figure $2 \mathrm{~A}, \mathrm{~B}$ ).

QVA149 showed a fast onset of action ( $5 \mathrm{~min}$ post-dose on day 1) with a significant $(p<0.0001)$ increase in $\mathrm{FEV}_{1}$ over placebo, indacaterol $300 \mu \mathrm{g}$ and indacaterol $600 \mu \mathrm{g}$. A treatment difference of $141 \mathrm{ml}$ was observed between QVA149 and placebo at $5 \mathrm{~min}$ post-dose on day 1 . QVA149 also showed a significant $(p<0.05)$ increase in $\mathrm{FEV}_{1}$ over placebo, indacaterol $300 \mu \mathrm{g}$ and indacaterol $600 \mu \mathrm{g}$ at all other time points on day 1. Statistically significant $(p<0.05)$ increases in $\mathrm{FEV}_{1}$ between QVA149 and both placebo and indacaterol (300 and $600 \mu \mathrm{g}$ ) were observed at all post-baseline time points on day 7 (figure $3 \mathrm{~A}$ ) and day 1 (figure $3 \mathrm{~B}$ ).

Trough FVC on days 1 and 7 (table 2) and the FVC at all postbaseline time points were significantly greater for QVA149A compared with both doses of indacaterol and placebo $(p<0.05)$. Peak FEV 1 on days 1 and 7 and standardised FEV 1 AUC 5 min -4 h, and $5 \mathrm{~min}-23 \mathrm{~h} 45 \mathrm{~min}$ on day 1 and standardised $\mathrm{FEV}_{1}$ AUC $5 \mathrm{~min}-4 \mathrm{~h}, 5 \mathrm{~min}-12 \mathrm{~h}$ and $5 \mathrm{~min}-23 \mathrm{~h} 45 \mathrm{~min}$ on day 7 were also significantly greater in patients treated with OVA149 than in patients treated with placebo or indacaterol (table 2).

Table 1 Patient demographics and baseline characteristics

\begin{tabular}{|c|c|}
\hline & $\begin{array}{l}\text { Total } \\
N=153\end{array}$ \\
\hline Age (years), mean (SD) & $61.7(8.50)$ \\
\hline Male, n (\%) & $94(61.4)$ \\
\hline Duration of COPD (years), mean (SD) & $7.9(5.66)$ \\
\hline \multicolumn{2}{|l|}{ Smoking history, n (\%) } \\
\hline Ex-smokers & $79(51.6)$ \\
\hline Current smoker & $74(48.4)$ \\
\hline Estimated number of pack-years, mean (SD) & $52.4(32.83)$ \\
\hline \multicolumn{2}{|l|}{ Previous use of COPD medications } \\
\hline Long-acting anticholinergics (tiotropium) & $56(36.6)$ \\
\hline Long-acting $\beta_{2}$-agonists & $37(24.2)$ \\
\hline Pre-bronchodilator $\mathrm{FEV}_{1}(\mathrm{I})$, mean (SD) & $1.3(0.46)$ \\
\hline Post-bronchodilator $\mathrm{FEV}_{1}{ }^{*}(\mathrm{I})$, mean $(\mathrm{SD})$ & $1.5(0.49)$ \\
\hline Pre-bronchodilator $\mathrm{FEV}_{1} \%$ predicted, mean (SD) & $45.3(12.26)$ \\
\hline Post-bronchodilator $\mathrm{FEV}_{1}{ }^{*} \%$ predicted, mean (SD) & $52.2(11.97)$ \\
\hline $\mathrm{FEV}_{1}$ reversibility $(\%)$, mean (SD) & $17.2(14.17)$ \\
\hline Post-bronchodilator $\mathrm{FEV}_{1} / \mathrm{FVC}^{*}(\%)$, mean (SD) & $47.6(10.02)$ \\
\hline
\end{tabular}

*Measured following salbutamol $400 \mu \mathrm{g}$

COPD, chronic obstructive pulmonary disease; $\mathrm{FEV}_{1}$, forced expiratory volume in $1 \mathrm{~s}$; FVC, forced vital capacity. 

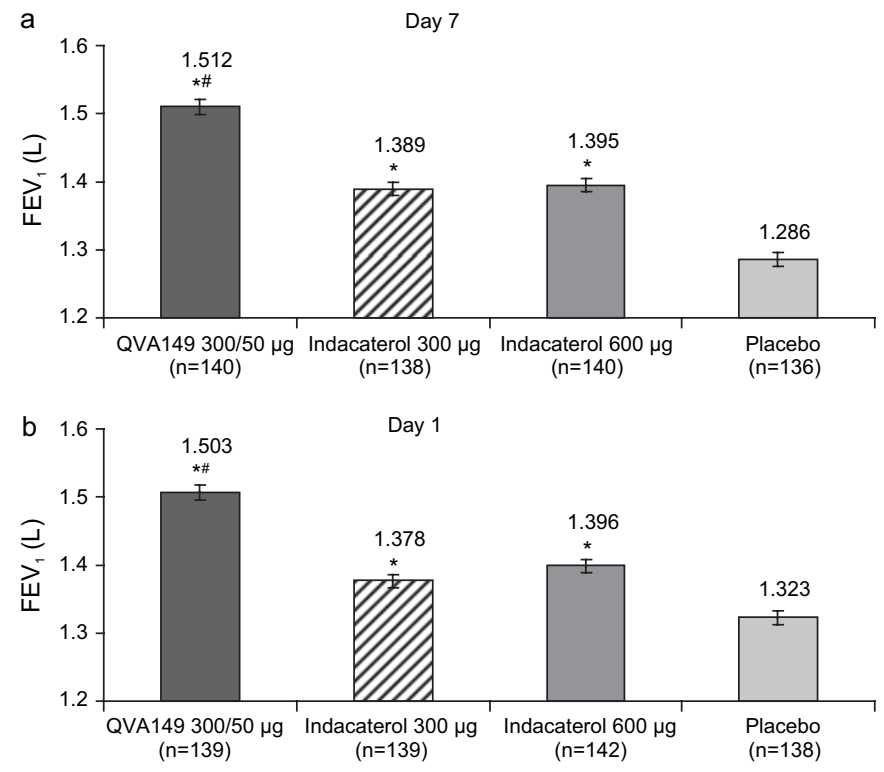

Data are least squares mean $\pm \mathrm{SE} ;{ }^{*} \mathrm{p}<0.0001$ vs placebo; ${ }^{*} \mathrm{p}<0.0001$ vs indacaterol $300 \mu \mathrm{g}$ and $600 \mu \mathrm{g}$

Figure 2 Trough forced expiratory volume in $1 \mathrm{~s}\left(\mathrm{FEV}_{1}\right)$ on $(\mathrm{A})$ day 7 (B) day 1.

The least squares means of IC and trough IC for OVA149 were significantly superior $(p<0.05)$ to all other treatments from $4 \mathrm{~h}$ post-dose on day 1 onwards (trough least squares mean (SE) 2.18 (0.019)). The least squares means of IC and trough IC for OVA149 were also statistically superior $(p<0.05)$ to all other treatments at all time points on day 7 (trough least squares mean (SE) 2.19 (0.021)) (table 2).

\section{Rescue medication}

The use of rescue medication was generally higher in patients receiving placebo compared with the active treatments. The number of puffs used was similar for the three active treatments. The number of patients using rescue medication was slightly higher in the OVA149-treated patients during day $1 / 2$ (9.2\%) compared with indacaterol $300 \mu \mathrm{g}(7.8 \%)$ and indacaterol $600 \mu \mathrm{g}(4.2 \%)$. However, during day $7 / 8$, it was slightly lower in a

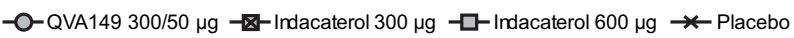
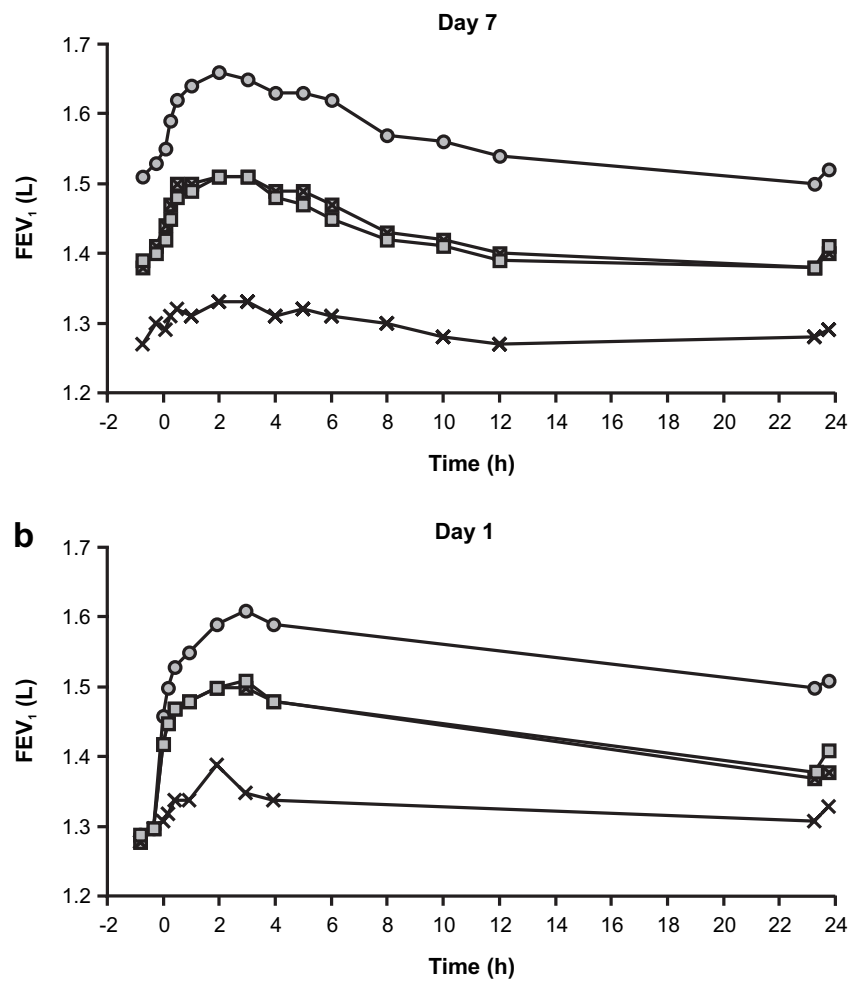

Data are least squares mean. QVA149 300/50 $\mu$ statistically superior $(p<0.05)$ to indacaterol $300 \mu \mathrm{g}$ and $600 \mu \mathrm{g}$ and placebo at all post-baseline time points

Figure 3 Forced expiratory volume in $1 \mathrm{~s}\left(\mathrm{FEV}_{1}\right)$ at all time points on (A) day 7 (B) day 1.

the OVA149 300/50 $\mu$ g-treated patients (9.3\%) compared with indacaterol $300 \mu \mathrm{g}(11.4 \%)$ and indacaterol $600 \mu \mathrm{g}(11.4 \%)$.

\section{Safety}

The majority of AE were mild in severity and were not suspected to be study drug related. The proportion of patients experiencing AE was similar between QVA149 and indacaterol $600 \mu \mathrm{g}$. Fewer patients experienced AE with indacaterol $300 \mu \mathrm{g}$ and placebo

Table 2 Bronchodilatory assessments (trough FVC, peak FEV 1 and standardised FEV 1 AUC and trough IC) at days 1 and 7 (mITT population)

\begin{tabular}{|c|c|c|c|c|}
\hline & $\begin{array}{l}\text { QVA149 300/50 } \mu \mathrm{g} \\
\mathrm{N}=142\end{array}$ & $\begin{array}{l}\text { Indacaterol } 300 \mu \mathrm{g} \\
\mathrm{N}=140\end{array}$ & $\begin{array}{l}\text { Indacaterol } 600 \mu \mathrm{g} \\
\mathrm{N}=142\end{array}$ & $\begin{array}{l}\text { Placebo } \\
N=140\end{array}$ \\
\hline \multicolumn{5}{|l|}{ Least squares mean (SE) } \\
\hline \multicolumn{5}{|l|}{ Day 1} \\
\hline Trough FVC (I) & $3.316(0.021)^{*}$ & $2.964(0.021)$ & $2.978(0.021)$ & $2.873(0.021)$ \\
\hline Peak FEV 1 & $1.659(0.014)^{*}$ & $1.567(0.015)$ & $1.559(0.014)$ & $1.423(0.015)$ \\
\hline Standardised $\mathrm{FEV}_{1} \mathrm{AUC}_{5 \mathrm{~min}-4 \mathrm{~h}}$ & $1.576(0.013)^{*}$ & $1.487(0.014)$ & $1.490(0.013)$ & $1.345(0.014)$ \\
\hline Standardised $\mathrm{FEV}_{1} \mathrm{AUC}_{5 \mathrm{~min}-23 \mathrm{~h}} 45 \mathrm{~min}$ & $1.548(0.012)^{*}$ & $1.440(0.012)$ & $1.444(0.012)$ & $1.330(0.012)$ \\
\hline Trough IC (I) & $2.180(0.019)^{*} \dagger$ & $2.092(0.019)$ & $2.102(0.019)$ & $2.029(0.019)$ \\
\hline \multicolumn{5}{|l|}{ Day 7} \\
\hline Trough FVC (I) & $3.148(0.023)^{*}$ & $2.956(0.024)$ & $2.968(0.023)$ & $2.819(0.024)$ \\
\hline Peak FEV 1 & $1.709(0.020)^{*}$ & $1.579(0.020)$ & $1.573(0.020)$ & $1.394(0.020)$ \\
\hline Standardised $\mathrm{FEV}_{1} \mathrm{AUC}_{5 \mathrm{~min}-4 \mathrm{~h}}$ & $1.641(0.019)^{*}$ & $1.505(0.019)$ & $1.495(0.019)$ & $1.320(0.019)$ \\
\hline Standardised $\mathrm{FEV}_{1} \mathrm{AUC}_{5 \min -12 \mathrm{~h}}$ & $1.610(0.018)^{*}$ & $1.473(0.018)$ & $1.457(0.018)$ & $1.317(0.018)$ \\
\hline Standardised $\mathrm{FEV}_{1} \mathrm{AUC}_{5 \min -23 \mathrm{~h}} 45 \mathrm{~min}$ & $1.569(0.016)^{*}$ & $1.438(0.017)$ & $1.427(0.017)$ & $1.302(0.017)$ \\
\hline Trough IC (I) & $2.191(0.021)^{*}$ & $2.090(0.022)$ & $2.073(0.022)$ & $1.973(0.022)$ \\
\hline
\end{tabular}

${ }^{*} \mathrm{p}<0.0001$ for QVA149 300/50 $\mu \mathrm{g}$ versus placebo, indacaterol $300 \mu \mathrm{g}$ and indacaterol $600 \mu \mathrm{g}$.

$t \mathrm{p}<0.01$ for QVA149 $300 / 50 \mu \mathrm{g}$ versus indacaterol $300 \mu \mathrm{g}$ and indacaterol $600 \mu \mathrm{g}$.

AUC, area under the curve; FEV $_{1}$, forced expiratory volume in $1 \mathrm{~s}$; FVC, forced vital capacityl; IC, inspiratory capacity; mITT, modified intent-to-treat. 
Table 3 Summary of most frequent AE ( $>2 \%$ population)

\begin{tabular}{|c|c|c|c|c|}
\hline & $\begin{array}{l}\text { QVA149 } 300 / 50 \mu \mathrm{g} \\
\mathrm{N}=142\end{array}$ & $\begin{array}{l}\text { Indacaterol } 300 \mu \mathrm{g} \\
\mathrm{N}=141\end{array}$ & $\begin{array}{l}\text { Indacaterol } 600 \mu \mathrm{g} \\
\mathrm{N}=141\end{array}$ & $\begin{array}{l}\text { Placebo } \\
N=143\end{array}$ \\
\hline \multicolumn{5}{|l|}{$\mathrm{n}(\%)$} \\
\hline Total AE & $39(27.5)$ & $31(22.0)$ & $37(26.2)$ & $31(21.7)$ \\
\hline Cough & $4(2.8)$ & $1(0.7)$ & $3(2.1)$ & $2(1.4)$ \\
\hline Dyspnoea & $2(1.4)$ & $2(1.4)$ & $4(2.8)$ & $4(2.8)$ \\
\hline Headache & $7(4.9)$ & $2(1.4)$ & $6(4.3)$ & $2(1.4)$ \\
\hline Nasopharyngitis & $1(0.7)$ & $6(4.3)$ & $2(1.4)$ & $5(3.5)$ \\
\hline Diarrhoea & $0(0.0)$ & $3(2.1)$ & $2(1.4)$ & $2(1.4)$ \\
\hline
\end{tabular}

$\mathrm{AE}$, adverse event.

(table 3). Two patients receiving QVA149 experienced serious AEs (fractured right arm and COPD exacerbation) and were discontinued from the study. None of the serious AEs were suspected of being related to the study drug. There were no clinically significant differences between the active treatments and placebo in terms of ECG evaluations, vital signs and laboratory evaluations. There was no difference between treatment groups with regard to the percentage of patients with notable OTC values (Fridericia's). No deaths were reported during the study.

\section{DISCUSSION}

This was the first study designed to assess the bronchodilatory effect of OVA149, a dual bronchodilator containing the LABA indacaterol and the LAMA NVA237 in patients with moderate to severe COPD. Following 7 days of treatment, once-daily QVA149 showed sustained 24-h bronchodilation that was significantly higher than placebo and indacaterol. The improvements in mean trough $\mathrm{FEV}_{1}$ exceeded the predefined minimal clinically important differences for QVA149 versus placebo and indacaterol. The onset of action of QVA149 was rapid as $\mathrm{FEV}_{1}$ was significantly higher compared with placebo and indacaterol at 5 min post-dose on days 1 and 7. QVA149 demonstrated significant improvements in all other spirometry results ( $\mathrm{FEV}_{1} \mathrm{AUC}$, peak $\mathrm{FEV}_{1}$, IC and FVC) compared with indacaterol or placebo. Both QVA149 and indacaterol treatment resulted in a reduction in rescue medication use compared with placebo. Results presented here are consistent with those published previously indicating that LABA/LAMA combinations provide statistically significant and clinically relevant improvements in bronchodilation and COPD symptoms over each individual bronchodilator. ${ }^{3} 681013$

A number of studies have assessed the efficacy and safety of tiotropium delivered in free combinations with formoterol. van Noord et $a l^{6}$ showed that a free combination of tiotropium plus formoterol given once daily in the morning was superior to twice-daily formoterol and once-daily tiotropium administered as monotherapies. Significant improvements in both day and night time $\mathrm{FEV}_{1}$ were obtained with combination compared with either monotherapy. In a longer-term study, it was shown that the addition of formoterol to tiotropium treatment conferred advantages in terms of early bronchodilator effect and lung function. ${ }^{10}$

The efficacy of indacaterol and NVA237 as once-daily therapies has been established. ${ }^{17-23}$ In our study, indacaterol produced similar and significant improvements in $\mathrm{FEV}_{1}$ compared with placebo; however, the addition of NVA237 to indacaterol produced substantial improvements in $\mathrm{FEV}_{1}$ over that achieved with either dose of indacaterol. The improvements in mean trough $\mathrm{FEV}_{1}$ obtained with OVA149 versus indacaterol $300 \mu \mathrm{g}$ and $600 \mu \mathrm{g}$ were $123 \mathrm{ml}$ and $117 \mathrm{ml}$, respectively. This effect of OVA149 appears to be additive and greater than the addition of arformoterol (15 $\mu \mathrm{g}$ twice daily) to tiotropium (18 $\mu \mathrm{g}$ once daily), which resulted in a $70 \mathrm{ml}$ improvement in trough $\mathrm{FEV}_{1}$ over either treatment alone. ${ }^{25}$ Once-daily indacaterol has been shown to provide clinically relevant $24-\mathrm{h}$ bronchodilation that was as effective as tiotropium. ${ }^{22}$ Therefore, the significant improvements with OVA149 over indacaterol monotherapy are of considerable importance.

OVA149 was well tolerated and no safety signals were identified. The combined bronchodilator approach in this study did not appear to increase the burden of AE. These results are consistent with other studies using LABA/LAMA combinations, ${ }^{36-8} 1013$ and for the monocomponents, indacaterol ${ }^{21-23}$ and NVA237. ${ }^{18}$ Future long-term studies will further assess the safety and tolerability profile of QVA149.

The results of this study also support the recommendations of current treatment guidelines that in patients with moderate, severe and very severe COPD, whose symptoms are not adequately controlled by maintenance monotherapy, bronchodilators of different classes can be combined. Such combinations may produce additional improvements in increasing the lung function and health status for equivalent or lesser side-effects. ${ }^{1}$ Most of the studies reported on LABA/LAMA combinations have focused on formoterol and salmeterol (both LABA, administered twice daily) and tiotropium (LAMA, once daily). ${ }^{3}$ 6-14 However, these studies were conducted on free combinations of bronchodilators. By using QVA149, a combination of indacaterol and NVA237, our study adds further evidence with respect to the improvements in bronchodilation and lung function obtained by the addition of two 24-h bronchodilators in a single inhaler.

By combining two long-acting bronchodilators, once-daily OVA149 may help to simplify COPD management by providing bronchodilatory benefits over twice-daily bronchodilators. Moreover, it is more convenient to use a drug once daily than twice daily. This can potentially improve patient compliance, tolerability and safety, all of which may lead to better outcomes. Because patient adherence is a major obstacle to successful management of COPD, simplified once-daily dosing regimens may improve compliance ${ }^{26} 27$ and reduce the dose frequency to the minimum necessary in order to maintain disease control. ${ }^{28}$

In conclusion, OVA149 was effective, well tolerated and demonstrated rapid and sustained 24-h bronchodilation in patients with moderate to severe stable COPD. QVA149 may offer a simplified and more convenient dosing regimen compared with taking the two compounds as separate agents. Ongoing and future studies will further establish the efficacy and safety of QVA149 in patients with COPD.

Acknowledgements The authors acknowledge and thank Shaik Asma Sultana, professional medical writer (Novartis), Mark Fedele (Novartis) and Gary Cotter (ACUMED UK) for assistance in the preparation of this manuscript. 
Funding This study was funded entirely by Novartis.

Competing interests JAvN is involved in carrying out contract research for Boehringer Ingelheim, GSK and Chiesi. RB has received reimbursement for attending scientific conferences, and/or fees for speaking and/or consulting from Novartis. He also has similar relationships with AstraZeneca, Boehringer Ingelheim, Chiesi, GlaxoSmithKline and Nycomed. CL is a member of the speaker's bureau for the following organisations: AstraZeneca, GlaxoSmithKline, Merck, Novartis, UCB Pharma, Sanofi-Aventis and Sepracor. He is also on the advisory boards at: GlaxoSmithKline, Schering-Plough, Alcon and Sepracor. CM, FJ, MD and TO are employees of Novartis.

Patient consent Obtained

Ethics approval This study was conducted with the approval of the independent ethics committee orinstitutional review board for each participating study centre.

Provenance and peer review Not commissioned; externally peer reviewed.

\section{REFERENCES}

1. GOLD. Global strategy for the diagnosis, management, and prevention of chronic obstructive pulmonary disease. http://www.goldcopd.com/ (accessed 2009).

2. Cazzola M, Matera MG. The effective treatment of COPD: anticholinergics and what else? Drug Discov Today Ther Strateg 2006:3:277-86.

3. Cazzola M, Santus P, Verga M, et al. The functional impact of adding salmeterol to tiotropium in patients with stable COPD. Respir Med 2004;98:1214-21.

4. Tashkin DP, Cooper CB. The role of long-acting bronchodilators in the management of stable COPD. Chest 2004;125:249-59.

5. Richter K, Stenglein S, Mucke M, et al. Onset and duration of action of formoterol and tiotropium in patients with moderate to severe COPD. Respiration 2006; 73:414-19.

6. van Noord JA, Aumann JL, Janssens E, et al. Comparison of tiotropium once daily, formoterol twice daily and both combined once daily in patients with COPD. Eur Respir J 2005a;26:214-22.

7. van Noord J, Aumann L, Janssens E, et al. Combination therapy of tiotropium plus salmeterol superior to single agent therapy in terms of dyspnea improvement in COPD (Abstract). Chest 2005b;128:177S

8. van Noord JA, Aumann JL, Janssens E, et al. Effects of tiotropium with and without formoterol on airflow obstruction and resting hyperinflation in patients with COPD. Chest 2006;129:509-17.

9. Rabe KF, Timmer W, Sagkriotis A, et al. Comparison of a combination of tiotropium plus formoterol to salmeterol plus fluticasone in moderate COPD. Chest 2008:134:255-62.

10. Vogelmeier C, Kardos P, Harari S, et al. Formoterol mono- and combination therapy with tiotropium in patients with COPD: a 6-month study. Respir Med 2008:102:1511-20.

11. Brashier B, Jantikar A, Maganji M, et al. Addition of formoterol to tiotropium produces better FEV ${ }_{1}$ and FVC responses when measured over 24 hours following single-dose administration in subjects with moderate-to-severe COPD (Abstract). Chest 2005;128:258s.
12. Cazzola M, Noschese P, Salzillo A, et al. Bronchodilator response to formoterol after regular tiotropium or to tiotropium after regular formoterol in COPD patients. Respir Med 2005;99:524-8

13. Tashkin DP, Littner M, Andrews $\mathrm{CP}$, et al. Concomitant treatment with nebulized formoterol and tiotropium in subjects with COPD: a placebo-controlled trial. Respir Med 2008:102:479-87.

14. Tashkin D, Pearle J, lezzoni D, et al. Treatment with formoterol plus tiotropium is more effective than treatment with tiotropium alone in patients with stable chronic obstructive pulmonary disease: findings from a randomized, placebo-controlled trial. J COPD 2009a; 6:17-25.

15. van Noord JA, de Munck DR, Bantje TA, et al. Long-term treatment of chronic obstructive pulmonary disease with salmeterol and the additive effect of ipratropium. Eur Respir J 2000;15:878-85.

16. D'Urzo AD, De Salvo MC, Ramirez-Rivera A, et al. In patients with COPD, treatment with a combination of formoterol and ipratropium is more effective than a combination of salbutamol and ipratropium. Chest 2001;119:1347-56.

17. Beier J, Chanez P, Martinot JB, et al. Safety, tolerability and efficacy of indacaterol a novel once-daily $\beta_{2}$-agonist, in patients with COPD: a 28-day randomised, placebo controlled clinical trial. Pulm Pharmacol Ther 2007;20:740-9.

18. Vogelmeier C, Verkindre C, Cheung D, et al. Safety and tolerability of NVA237, a once-daily long-acting muscarinic antagonist, in COPD patients. Pulm Pharmacol Ther 2010;23:438-44.

19. Rennard S, Bantje T, Centanni S, et al. A dose-ranging study of indacaterol in obstructive airways disease, with a tiotropium comparison. Respir Med 2008;102:1033-44.

20. Verkindre C, Fukuchi Y, Flémale A, et al. Sustained 24-h efficacy of NVA237, a once daily long-acting muscarinic antagonist, in COPD patients. Respir Med 2010:104:1482-9.

21. Dahl R, Chung KF, Buhl $R$, et al. Efficacy of a new once-daily long-acting inhaled $\beta_{2}$-agonist indacaterol versus twice-daily formoterol in COPD. Thorax 2010:65:473-9.

22. Donohue JF, Fogarty C, Lötvall J, et al. Once-daily bronchodilators for chronic obstructive pulmonary disease: indacaterol versus tiotropium. Am J Respir Crit Care Med 2010:182:155-62.

23. Feldman G, Siler T, Prasad N, et al. Efficacy and safety of indacaterol $150 \mu \mathrm{g}$ once-daily in COPD: a double-blind, randomised, 12-week study. BMC Pulm Med 2010:10:11.

24. Cazzola M, MacNee W, Martinez FJ, et al. Outcomes for COPD pharmacological trials: from lung function to biomarkers. Eur Respir J 2008:31:416-68.

25. Tashkin DP, Donohue JF, Mahler DA, et al. Effects of arformoterol twice daily, tiotropium once daily, and their combination in patients with COPD. Respir Med 2009b;103:516-24.

26. Claxton AJ, Cramer J, Pierce CA. A systematic review of the associations between dose regimens and medication compliance. Clin Ther 2001;23:1296-310.

27. Bender BG. Overcoming barriers to nonadherence in asthma treatment. J Allergy Clin Immunol 2002;109(Suppl 6):S554-9.

28. Tamura G, Ohta K. Adherence to treatment by patients with asthma or COPD: comparison between inhaled drugs and transdermal patch. Respir Med 2007;101:1895-902. 